\title{
Effect of Artificial Aging on Polymeric Surge Arresters and Polymer Insulators for Electricity Distribution Networks
}

\author{
Carlos A. Ferreira, E. Coser \\ LAPOL/PPGE3M, UFRGS \\ Joceli M. G. Angelini \\ Departamento de Materiais Elétricos, CPqD
}

José A. D. Rossi

Materiais Alta Tensão, $C P q D$

\author{
Manuel L. B. Martinez \\ Departamento de Engenharia Elétrica, UNIFEI
}

\begin{abstract}
A study was conducted to evaluate new and laboratory-aged samples of surge arresters and anchorage polymeric insulators, for 12 and $24 \mathrm{kV}$ networks, which are used by the Rio Grande Energia (RGE). Power Utility Polymeric compounds were analyzed by Differential Scanning Calorimetry (DSC), Thermogravimetric Analysis (TG), Dynamic-Mechanic Analysis (DMA), Fourier Transformed Infrared Spectroscopy (FTIR) and Scanning Electronic Microscopy (SEM) to verify changes in the insulator properties due to degradation occurred during the experiments. The analyses were carried out before and after 6 months of aging in laboratory devices (weatherometer, $120^{\circ} \mathrm{C}$, salt spray, immersion in water). After the aging experiments, high-voltage electrical tests were also conducted: a radio interference voltage test and, simultaneously, the total and the internal leakage currents were measured to verify the surface degradation of the polymeric material used in the housing. The impulse current test was applied with current values close to 5,10 and $30 \mathrm{kA}$, in order to force an internal degradation. Results showed that only surface degradation is detected at the polymer. The main properties of the parts were not affected by the aging. It confirms that polymer insulator and surge arrestor are appropriate for use in electricity distribution networks.
\end{abstract}

Keywords: Polymeric arrester, silicone rubber insulators, silicone degradation, leakage current.

\section{Introduction}

The use of polymeric materials for manufacturing devices such as surge arresters, and anchoring insulators, for installation on electricity distribution ${ }^{[1]}$ network has been growing recently in Brazil. The polymeric materials which are being used increasingly for outdoor applications present better characteristics compared to porcelain and glass and therefore the behavior of these products must be well known and understood in order to optimize their performance for normal application in the field. They represent one of the most effective alternatives for reducing the rates of interruption especially in the southernmost state of Rio Grande do Sul, because of its particular climate and the large number of natural lightning discharges in the region. The application of polymer products has advantages such as ease of handling and installation in areas of difficult access and also lower incidence of vandalism. Moreover, silicone rubber (SR) has a larger hydrophobic surface compared to porcelain and glass, and thus a lower incidence of leakage current (LC) and power frequency flashover can be expected ${ }^{[2-4]}$.

However, there are still many questions concerning their long-term performance under natural conditions, especially when industrial or marine pollution is present. The polymeric materials used, e.g. SR age more rapidly than glass or porcelain. It is generally considered that SR housings, when properly chosen and formulated, usually provide the best insulator performance, although other materials may also behave satisfactorily ${ }^{[5]}$.

The hydrophobicity provided by SR prevents the formation of contaminated water film on the insulator surfaces, while in the case of porcelain or glass insulators water readily forms a continuous film on the hydrophilic surface ${ }^{[6]}$. In the presence of contamination, LC develop, which build up may result in a flashover of the insulator. In these cases water droplets are formed which simply run off the surface. However, this hydrophobicity can be lost temporarily during exposure to electrical discharges or even severe contamination. After a subsequent period of rest, the hydrophobicity usually regained ${ }^{[7]}$.

One of the main causes of aging is the development of leakage current (LC), which produces heating of the electrolytic layer on the wet contaminated insulator surface ${ }^{[8]}$. The effect of polymer degradation on surge arresters can lead to the loss of the equipment operational characteristic or to a failure on the distribution line.

To expand their application to power system networks, the material characteristics should be tested in the laboratory in order to check if new compounds are thermo and photo stable. Even for products already widely used in other regions and other countries, it is necessary to define their desirable characteristics, to determine the feasibility of their use.

Composite anchoring and suspension insulators consist of pultruded glass-reinforced composite cores, which are protected by a polymeric housing. The ends of the insulators are terminated by steel fittings which are mechanically fastened to the pultruded core and sealed to the polymeric housings.

Mechanical failure and electrical flashover are causes of failure of overhead polymeric insulators and surge arresters. Mechanical failure is catastrophic and irreversible. Insulators and surge arresters present this mode of failure, often due to poor sealing between the end fittings and the polymer allowing water ingress. Electrical flashover can result from transients on the network or of a reduction in an insulator's withstanding capability to operational stresses.

Autor para correspondência: Carlos A. Ferreira, Laboratório de Materiais Poliméricos, Departamento de Engenharia de Materiais, Universidade Federal do Rio Grande do Sul, Av. Bento Gonçalves, 9500, Setor 4, Prédio 74, sala 113, Agronomia, CP 15010, CEP 91501-970, Porto Alegre, RS, Brasil, e-mail: ferreira.carlos@ufrgs.br 
The insulator or surge arrester recovers from an electrical flashover, but such an occurrence at operational working stresses must be seen as a system failure. An insulator or surge arrester in such an event is considered as failed and has to be serviced or replaced ${ }^{[9]}$.

This study focuses on the polymers used for manufacturing surge arresters housings and insulators of distribution systems that may already be presenting problems of penetration obtained from samples installed in the field. New samples provided by the power utility (RGE power utility) were submitted to accelerate aging tests for 6 months (weatherometer, $120{ }^{\circ} \mathrm{C}$, water immersion and salt spray). Electrical tests were carried out to monitor the polymer degradation and mechanical, chemical and physico-chemical variations. Physicochemical and electrical properties of samples taken from the field were also analyzed considering the time and area of installation. Analysis of failures were also performed on surge arresters and insulators from different regions of the state of Rio Grande do Sul and that had presented problems in the field. These results were then compared with those of the new devices as a function of time and place of installation.

The surge arresters and insulators were analyzed at $\mathrm{t}=0$ (without aging) and after 6 months of aging by several techniques. The thermal analysis (TGA, DSC, and DMA) investigated the behavior of a material as a function of temperature. FTIR spectroscopy was used to determine whether degradation had occurred in the internal or external parts of the surge arresters and the insulators. This is very useful in the study of compositional changes and the growth of cracks, crazing or fissures. In order to verify the surface degradation conditions of the materials used in surge arresters housings, samples were also subjected to radio interference voltage, and leakage current tests.

\section{Specimens}

The surge arresters and insulators tested in this study were made of high temperature vulcanized (HTV) SR cured at $160-170{ }^{\circ} \mathrm{C}$, which is a mixture of a base silicone (polydimethylsiloxane) polymer and silicone gum with a molecular weight between 300,000 and 700,000 g. $\mathrm{mol}^{-1}$.

Crosslinking of the polymer takes place through decomposition of peroxides at temperatures of $100{ }^{\circ} \mathrm{C}$. The peroxides decompose into free radicals which react with unsaturated bonds or even with methyl groups by abstraction of hydrogen atoms ${ }^{[7]}$.

Polymeric housings of the surge arresters are filled with alumina trihydrate $\left(\mathrm{ATH} \mathrm{Al}_{2} \mathrm{O}_{3} 3 \mathrm{H}_{2} \mathrm{O}\right.$ ) that helps to prevent tracking and to limit the erosion of the material. This is generally considered as the main defense mechanism in preventing the development of leakage current that is a precursor to fire $\operatorname{arcing}^{[2-5,10]}$.

\section{Experimental}

The new samples and samples removed from the field are displayed in Figure 1 and Figure 2 respectively. Some studies have being carried out on silicone rubber used in the housing, obtained in the same way and subjected to the same aging conditions as the surge arresters. A, B, C, D and S denotes the different sample suppliers.

\section{Accelerated tests}

The new samples, where time of aging was zero $(t=0)$, were evaluated before artificial aging in terms of their electrical (current leakage and others), chemical, physical and thermal properties. They were exposed to artificial aging procedures over 6 months and then reevaluated to estimate the degradation by aging.

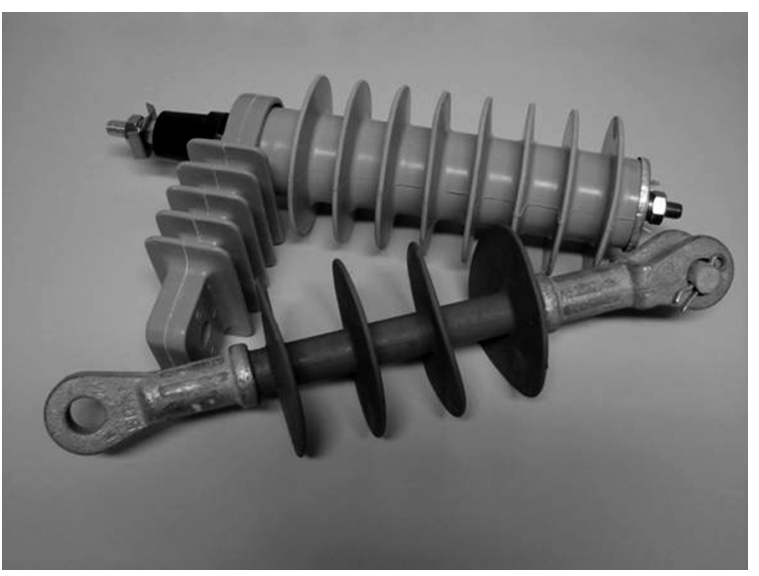

Figure 1. New products from Campo Bom, Brazil: silicone anchoring insulators and silicone surge arresters.
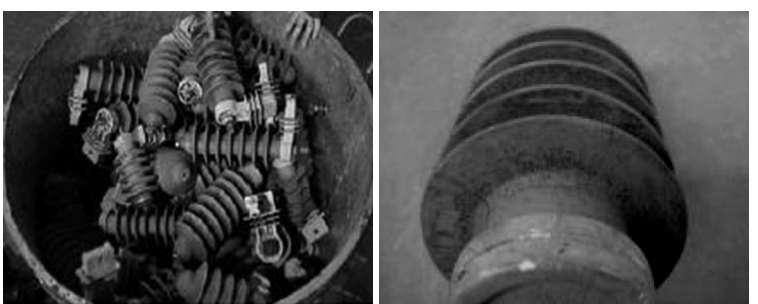

Figure 2. SR surge arresters and insulators with problems taken from the field.

\section{Weatherometer}

Tests were carried out using a $6500 \mathrm{~W}$ Xenon arc lamp, with borosilicate filters. The irradiation intensity was $0.35 \mathrm{~W} . \mathrm{m}^{-2}$ at $340 \mathrm{~nm}$; as the standard ASTM G26 - 96 $6^{[11]}$, the black panel temperature during test was $63{ }^{\circ} \mathrm{C}$. Cycles were: 120 minutes, using 102 minutes of light followed by 18 minutes of light and water spray, repeated periodically. No relative humidity control was done.

\section{Thermal aging}

Samples were placed in a Fanem model 320-E oven and maintained at $120^{\circ} \mathrm{C}$ for 6 months.

\section{Immersion in water at room temperature}

Figure 3 shows the new samples during imersion into water at room temperature for 6 months.

\section{Salt spray}

Salt spray test was conducted according to ASTM B $117-07 \mathrm{a}^{[12]}$ using a BASS model USC chamber maintained at $35 \pm 2{ }^{\circ} \mathrm{C}$. Surface degradation was evaluated by daily visual observations of the samples. After the 6 month no visual erosion of SR was remarked in agreement with other authors ${ }^{[13-14]}$. Only metallic parts (galvanized steel) were corroded, as shown in Figure 4.

\section{Electrical stress}

Leakage current (LC) measurements were carried out to evaluate the performance and degree of aging of polymeric insulators in laboratory and field studies.

\section{Degradation measurements techniques}

Tests were carried out on new samples $(t=0)$, samples with problems in the field, and samples after artificial aging in the laboratory for monitor the accelerated and natural degradation. 


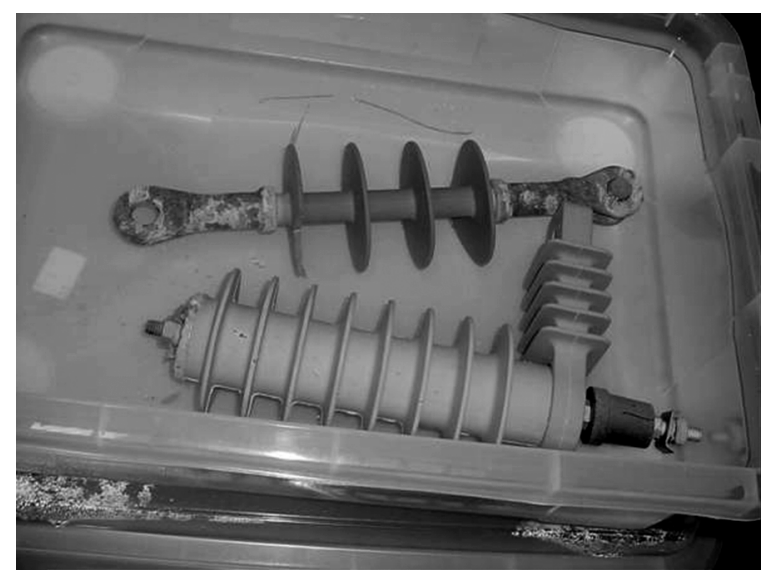

Figure 3. Samples immersed in water at room temperature.

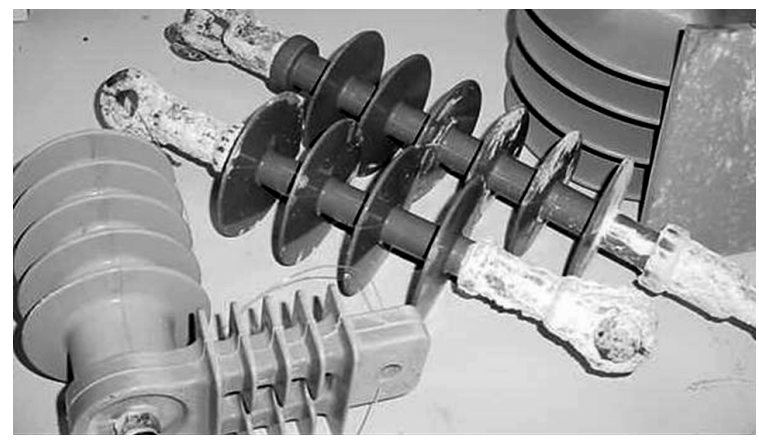

Figure 4. Aspect of samples after 6 months in salt spray.

\section{Thermal analysis}

Differential scanning calorimetry (DSC) data were obtained in a TA Instruments model 2910 DSC using a scan rate of $10^{\circ} \mathrm{C} / \mathrm{min}$ in the temperature range of -150 to $300{ }^{\circ} \mathrm{C}$.

The Thermogravimetric analyses (TG) were realized in a TA Instruments Model 2050 TGA operating under $\mathrm{N}_{2}$ atmosphere. The samples were heated from 25 to $1000{ }^{\circ} \mathrm{C}$ with heating rate of $20{ }^{\circ} \mathrm{C} / \mathrm{min}$.

The Dynamic-mechanical analysis (DMA) were carried out in a TA Instruments model 2980 under $\mathrm{N}_{2}$ atmosphere with heating rate of $10{ }^{\circ} \mathrm{C} / \mathrm{min}$, in the temperature range -150 to $100{ }^{\circ} \mathrm{C}$ and $1 \mathrm{~Hz}$ frequency.

The same equipment was used to determine Vicat temperature according to the standard method ASTM D 1525-98 ${ }^{[15]}$. In this test it is determined the temperature at which a flat-ended needle of $1 \mathrm{~mm}^{2}$ circular section penetrate a polymer specimen to a depth of $1 \mathrm{~mm}$ under a specified load using a selected uniform rate of temperature rise.

\section{Infrared analysis}

The samples were analyzed in a Perkin Elmer model Spectrum 100 by transmittance and using an Attenuated Total Reflectance accessory, the standard method ASTM E1252- 98 ${ }^{[16]}$.

\section{Scanning electronic microscopy}

The samples were also analyzed by Scanning Electron Microscopy using a Jeol model JSN 6060 microscope that permitted evaluation of silicone morphology.

\section{Electrical tests}

Radio Interference Voltage (RIV): is used to measure the levels of radio interference between 0.8 and $1.1 \mathrm{(pu}$ ) of the surge arrester rated voltage according to NEMA $107^{[17]}$. The results of the radio interference voltage are indicative of the design quality of the surge arrester and serve as a basis for verification of mechanical structural degradation after current stresses with standard shapes of 8/20 and 4/10 as required by IEC60.099-4 - "Metal-oxide surge arresters without gaps for AC systems".

The leakage current tests were carried out with and without the application of a conductive tape connected to the base of the surge arresters. In such cases, the internal leakage current, or leakage through the resistors and the total leakage current of the surge arresters were measured. The internal leakage current is obtained with grounded conductive tape. An external leakage current is the difference between the total and the internal leakage current and is obtained with grounded conductive tape.

After the initial RIV and leakage current tests, the samples were submitted to the lightning impulse test as requirement by IEC $60.099-4$, with current amplitudes of 5, 10 and $30 \mathrm{kA}$. These tests were performed on new and aged samples and the results for the aged samples were as expected. After a second series of RIV and leakage current tests, each sample was installed in an artificial rain and salt spray chamber and the leakage current test was repeated under conditions of salt spray and rain.

\section{Results and Discution}

\section{Electrical}

Aging of SR insulators can be provoked by the circulation of leakage current, producing heating of the wet contaminated insulator surface. The power of dissipation and density of the current are not uniform along the insulator surface. The water is evaporated in the higher current region forming narrow dry bands, causing significant fluctuations in the voltage distribution along the insulator. As a consequence, electrical discharges of relatively large magnitudes occur, dynamically bridging the dry bands, a phenomenon commonly known as dry-band arcing. Under certain conditions, the arc can become long enough to bridge the gap between the surge arresters ends causing flashover.

The measurements of Radio Interference Voltage - RIV were performed on all analyzed samples, before and after the lightning impulse tests up to $30 \mathrm{kA} 8 \times 20 \mu$ s and after artificial weather aging. The discharge and RIV tests did not show evidence of the existence of structural degradation of the samples due to surges. The results of the leakage current test, a specific way of field evaluation of metal oxide arresters, on new, aged in the laboratory and removed samples from the field, are given in Table 1. From all the obtained data it was chosen, in this paper, to present and discuss the results of electrical tests of supplier A, considered as representative of all the others (see arrangement to the test at Figure 5).

Results obtained for leakage current of the aged sample of supplier A, a typical observed result in laboratory, did not show large deviation compared to the new sample. The greatest deviations occurred in the case of the two surge arrester removed from the field after four years of installation in the region of Caxias do Sul (Brazil).

Surge arresters removed from the field due to problems also presented high leakage current. This may be due to the presence of films of water on the surface of the surge arrester silicone housings. However, it is necessary to emphasize that, considering the results of the visual inspections, the housings presented a good degree of hydrophobicity. The values for the external leakage currents under fog were higher than those under rain, with a performance similar to that observed for polymeric insulators. The values obtained were higher under fog conditions and substantially higher than under dry conditions. The external leakage currents under fog conditions reached maximum values of 700 to $1196 \mu \mathrm{A}$. 
Table 1. Leakage Current Maximum (LCM ) for the surge arresters.

\begin{tabular}{lcccc}
\hline \multicolumn{1}{c}{ Samples (aging) } & $\begin{array}{c}\text { External LCM } \\
(\mathbf{d r y})(\boldsymbol{\mu A})\end{array}$ & $\begin{array}{c}\text { External LCM } \\
(\text { under spray })(\boldsymbol{\mu A})\end{array}$ & $\begin{array}{c}\text { Total LCM } \\
(\mathbf{d r y})(\boldsymbol{\mu A})\end{array}$ & $\begin{array}{c}\text { Total LCM } \\
(\mathbf{u n d e r} \mathbf{s p r a y})(\boldsymbol{\mu A})\end{array}$ \\
\hline Surge arrester A (new) & 50 & 104 & 160 & 368 \\
Surge arrester A (immersed in water) & 20 & 128 & 244 & 760 \\
Surge arrester A (aged at $\left.120^{\circ} \mathrm{C}\right)$ & 32 & 1196 & 1064 & 2220 \\
Surge arrester A (aged in weatherometer) & 168 & 376 & 440 & 1088 \\
Surge arrester A (used 4 years in the region & 28 & 1020 & 536 & $10600 / 17200$ \\
of Caxias do Sul) & 40 & 700 & 1920 & 8900 \\
Surge arrester A (with problem) & & & & \\
\hline
\end{tabular}

Table 2. Infrared Spectroscopy comments (A, B, C, D and S represent the different suppliers).

\begin{tabular}{|c|c|}
\hline Samples & FTIR information \\
\hline New silicone rubber & Absorption in range of $1259-1397 \mathrm{~cm}^{-1}$ \\
\hline Surge arrester A after Weatherometer & Absorption of hydroxyl \\
\hline Surge arrester $\mathrm{A}$ in water & Reduction in hydroxyl absorption \\
\hline Surge arrester A in salt spray & Decrease in hydroxyl absorption \\
\hline $\begin{array}{l}\text { Insulator } \mathrm{B}, 12 \mathrm{kV} \text {, after water, salt spray, Weatherometer, } \\
\text { application of high temperature }\left(120^{\circ} \mathrm{C}\right)\end{array}$ & Absence of hydroxyl \\
\hline $\begin{array}{l}\text { Insulator } \mathrm{C}, 24 \mathrm{kV} \text {, after water, salt spray, Weatherometer, } \\
\text { application of high temperature }\left(120^{\circ} \mathrm{C}\right)\end{array}$ & Absence of hydroxyl \\
\hline Insulator D after 3 years in field, Caxias do Sul & There was a detachment of waste \\
\hline Insulator S after 3 years in field, Caxias do Sul & Presence of hydroxyl and absorption \\
\hline Surge arrester A, Caxias do Sul, (urban region) 4 years in the field & Absence of hydroxyl \\
\hline Surge arrester A, Caxias do Sul, (non urban region) 4 years in the field & Absence of hydroxyl \\
\hline Surge arrester A, Taquara, 6 years in the field & There were no significant changes for the new samples \\
\hline
\end{tabular}

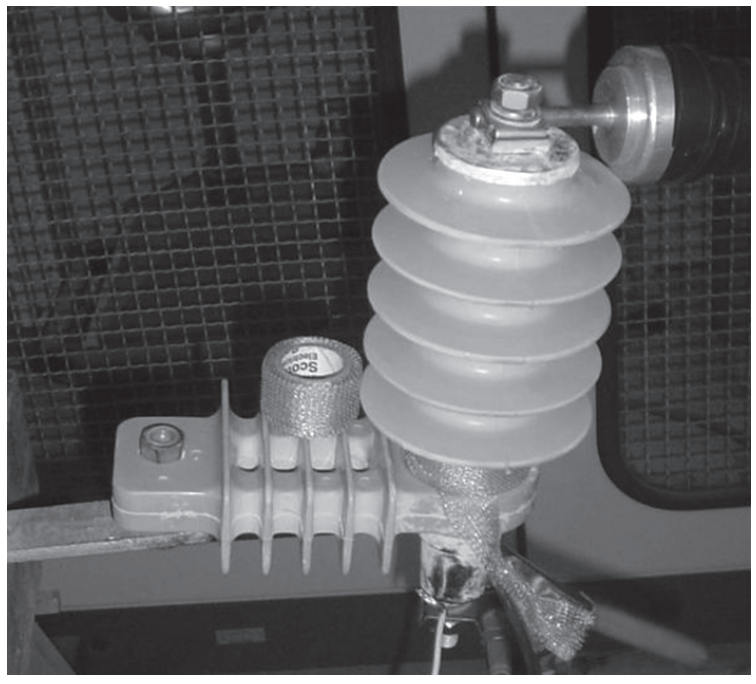

Figure 5. Arrangement for measuring internal leakage current.

Used surge arresters displayed leakage currents values similar to new surge arresters of the same rated voltage, before and after application of the current. However, the used and new surge arresters did show a significant difference in the leakage current for tests on spray and dry conditions. The values for internal leakage current follow the external current.

\section{FTIR spectrometry}

The infrared spectroscopy analysis showed that the SR degradation products were constituted of hydroxyls. Results obtained from the FTIR spectra for the surge arrester and insulators sample of 12 and $24 \mathrm{kV}$ are displayed in Table 2.

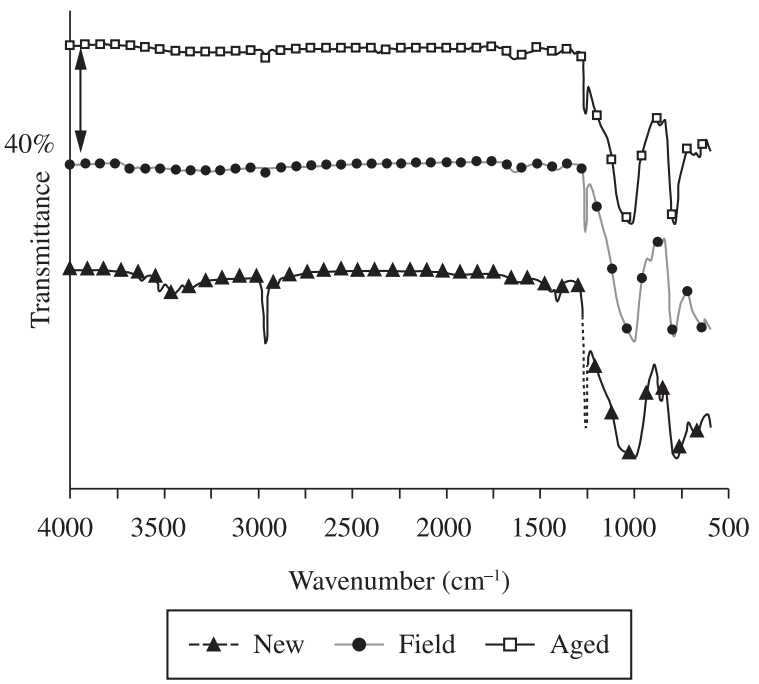

Figure 6. FTIR spectrum for the surge arresters new, 6 months of aging in salt spray end surge arresters with 4 years in the field.

The Figure 6 shows the spectra obtained for samples of SR identified as new aged (salt spray) and removed from field.

Absorption was observed in the region of 3300 to $3600 \mathrm{~cm}^{-1}$, resulting from $\mathrm{OH}$ groups of the alumina trihydrate (ATH) present in the silicon rubber. There was a reduction in the intensity of these bands in the samples aged and removed from the field when compared with the new sample. This phenomenon could be attributed to the loss of ATH filler (chalking) and scission of $\mathrm{C}-\mathrm{H}$ in $\mathrm{CH}_{3}$ bonds.

The band at $2962 \mathrm{~cm}^{-1}$ is due to aliphatic $\mathrm{C}-\mathrm{H}$ stretching in $\mathrm{CH}_{3}$, and that at $1270-1255 \mathrm{~cm}^{-1}$ is attributed to symmetric 


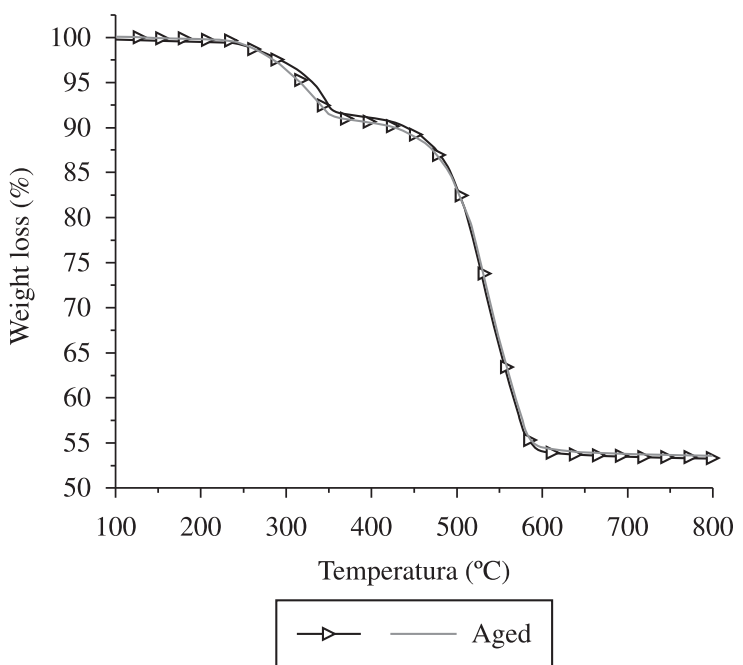

Figure 7. TGA thermograms for new and aged silicone surge arresters A $12 \mathrm{kV}$.

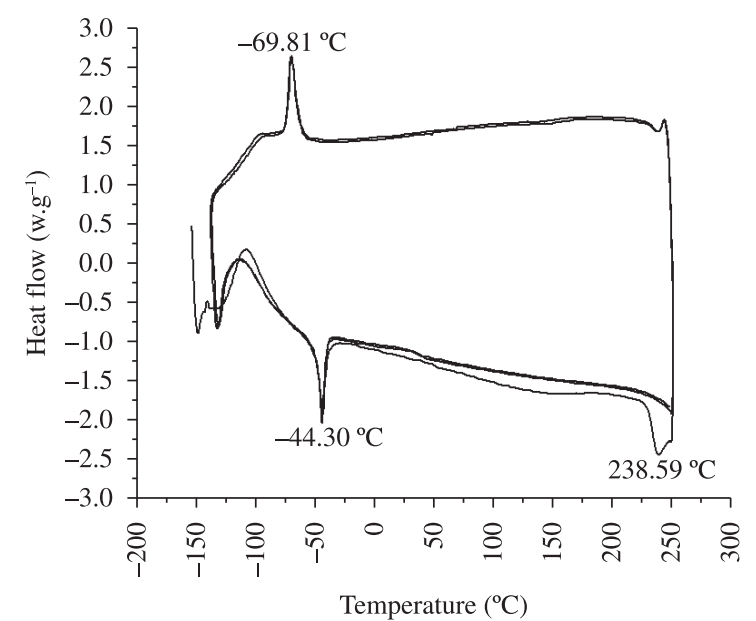

Figure 8. DSC analysis of new silicone surge arresters A $24 \mathrm{kV}$ (exothermic phenomena up).

$\mathrm{CH}$ deformation of $\mathrm{Si}-\mathrm{CH}_{3}$. The intense absorption at around $1000-1100 \mathrm{~cm}^{-1}$ can be assigned to the Si-0-Si stretching, which shows no significant alteration, indicating that the samples can recover their hydrophobicity easier, than the new samples ${ }^{[18]}$.

In the case of aged SR in salt spray and in the field, there was a great reduction in absorbance intensity of bands originated from $\mathrm{Si}-\mathrm{CH}_{3}$ and $\mathrm{CH}_{3}$ vibration compared with new samples spectrum ${ }^{[19]}$.

\section{Thermogravimetry}

Thermogravimetric analysis (TGA) was used to evaluate the thermal stability of the polymer used to manufacture polymeric surge arresters. All of the aging (salt spray, in water, Weatherometer and temperature $120{ }^{\circ} \mathrm{C}$ ) were compared with new sample, we observed that no change occurred in sample.

The TGA thermograms of the new and aged samples are shown in Figure 7. It indicates that surge arresters do not present thermal decomposition if heated until $250{ }^{\circ} \mathrm{C}$.

Figure 7 shows TGA thermograms: a first decomposition occurred in the range of temperature between 248 to $350{ }^{\circ} \mathrm{C}$ with a mass loss of $10 \pm 2 \%$, which can be attributed to the loss of the water of hydration of ATH. In the temperature range of 400 to $550{ }^{\circ} \mathrm{C}$ a loss of mass of $35 \pm 2 \%$ occurs and can be attributed to the polymer
Table 3. TGA results of the various suppliers (A, B, C).

\begin{tabular}{lcccc}
\hline \multirow{2}{*}{ Samples } & \multicolumn{2}{c}{ Decomposition 1 } & \multicolumn{2}{c}{ Decomposition 2 } \\
\cline { 2 - 5 } & ${ }^{\circ} \mathbf{C}$ & \% & ${ }^{\circ} \mathbf{C}$ & \% \\
\hline Surge arrester A 24 kV & 349.0 & 8.1 & 536.0 & 39.0 \\
Insulator B 12 kV & 348.5 & 9.5 & 534.8 & 37.8 \\
Insulator C 12 kV & 348.5 & 9.5 & 532.8 & 37.7 \\
\hline
\end{tabular}

Table 4. DSC data for new and aged surge arresters.

\begin{tabular}{lccc}
\hline \multicolumn{1}{c}{ Samples } & $\begin{array}{c}\text { Melting } \\
\text { temperature } \\
\left({ }^{\circ} \mathbf{C}\right)\end{array}$ & $\begin{array}{c}\text { Temperature of } \\
\text { crystallization } \\
\left({ }^{\circ} \mathbf{C}\right)\end{array}$ & $\begin{array}{c}\text { Cure or } \\
\text { decomposition }\end{array}$ \\
\hline A 12 kV new & -44.3 & -70.0 & 238.6 \\
A 24 kV new & -44.9 & -70.5 & 240.9 \\
A 12 kV water & -45.8 & -74.0 & 240.1 \\
B 12 kV after & -45.0 & -74.8 & 240.6 \\
weatherometer & & & \\
A 12 kV after & -45.6 & -79.6 & 244.7 \\
salt spray & & &
\end{tabular}

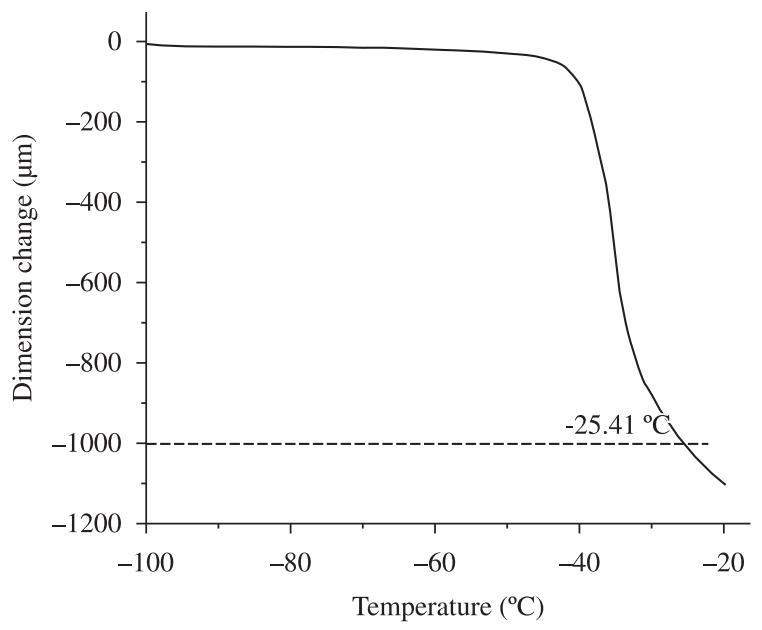

Figure 9. Vicat temperature, SR new.

degradation. A residual content of $53 \pm 1 \%$ has been obtained and is due to the presence of the inorganic filler at the sample.

In the Table 3, can be observed the percentage of residue from different suppliers. The samples from suppliers A, B and C show similar stability, displaying two thermal events as described in Table 3. Samples from suppliers D and S were not analyzed because according to RGE, they are presently out of the market.

DSC

The DSC is a method of direct and quantitative measurement of heat transfer and the changes in enthalpy involved in transitions experienced by the material.

DSC thermogram showed two endothermic events and one exothermic event (Figure 8). The first endothermic event at $-44{ }^{\circ} \mathrm{C}$ can be attributed to melting temperature of crystalline phase of SR and the exothermic event at $-70{ }^{\circ} \mathrm{C}$ correspond to the crystallization of SR. Endothermic event at around $240{ }^{\circ} \mathrm{C}$ is due to the start of decomposition of the polymer. This data is in accordance with previous TG data ${ }^{[15]}$. The DSC temperatures for the new and aged surge arresters showed no significant change, as shown in the Table 4. 
$D M A$

A typical Vicat softening temperature experiment determined with DMA is displayed in Figure 9.

Vicat tests of the new and aged samples are shown in Table 5. New samples displayed Vicat temperature of $-21.07{ }^{\circ} \mathrm{C}$ and -17.5 , the difference being attributed to different producers. Vicat temperature diminishes after aging of SR indicating that the samples became softer near the surface (Vicat needle penetrates only $1000 \mu \mathrm{m}$ ), due to decomposition of polymer chains at high temperature.

In DMA analysis the maximum of viscous modulus (or loss modulus, $\varepsilon$ ") in particular, and also, the maximum $\tan \delta$ values ( $\tan$ $\delta=\varepsilon$ “' $\varepsilon$ '), are used to determine the glass transition temperature (Tg) of polymer. Variations greater that $20 \%$ in the $\mathrm{Tg}$ by $\tan \delta$ can be observed in samples after aging for 6 months in the laboratory and four years in the field ${ }^{[15]}$.

The ability of a polymeric material to withstand loads at high temperatures is one of the key aspects of engineering performance to be studied. DMA is a method that measures the stiffness (shear, tensile, flexural module) and mechanical damping, i.e. internal friction or dissipation (loss) factor $\tan \delta$ as a function of temperature.

Table 5. Vicat temperature $\left({ }^{\circ} \mathrm{C}\right)$ according to ASTM D 1525-98.

\begin{tabular}{lc}
\hline \multicolumn{1}{c}{ Sample } & Vicat softening point $\left({ }^{\circ} \mathbf{C}\right)$ \\
\hline A $12 \mathrm{kV}$ & $-22,40$ \\
B 24 kV & $-21,10$ \\
New silicone rubber & $-22,50$ \\
Aged silicone rubber (Weatherometer) & $-21,12$ \\
Aged silicone rubber (salt spray) & $-17,50$ \\
\hline
\end{tabular}

The technique gives information on the elastic modulus (or storage modulus, $\varepsilon^{\prime}$ ), which defines the energy stored in a specimen due to an applied strain and on the viscous modulus ( $\varepsilon$ "), associated to the dissipation of energy stored by a polymer. In a dynamic experiment, when equilibrium is reached and viscoelastic behavior is linear, both stress and strain vary sinusoidally, but strain lags behind stress ${ }^{[14]}$.

Figure 10 shows the behavior of salt spray aged samples analyzed from -150 to $50{ }^{\circ} \mathrm{C}$ at a heating rate of $5{ }^{\circ} \mathrm{C} / \mathrm{min}$ ( $1 \mathrm{~Hz}$ frequency). This test was performed before and after aging (only aged samples showed). Samples displayed similar results in both situations. Glass transition temperature of the silicone rubber sample determined by the peak of the $\tan \delta$ is located at $-111^{\circ} \mathrm{C}$.

\section{Photomicrographs}

Visual inspection of surface of insulators and surge arresters has not evidenced occurrence of erosion in any of the samples. However, only loss of brightness and fade were observed as an evidence of degradation.

The samples of the silicone insulator and silicone surge arrester surfaces were examinated by scanning electron microscopy (SEM). The sample surfaces were first coated with a thin gold layer, to show the morphological structures of the polymer products under study, which are related to the mechanical properties of the final products. The occurrence of microscopic erosion at the samples aged according to the description below has been remarked ${ }^{[18]}$.

Figure 11 shows SEM photomicrographs of the surface of the new samples (Figure 11a) and the samples aged in salt spray insulator (Figure 11b). In the Figure 11a ATH particles have been observed at the surface of the new samples indicating a good

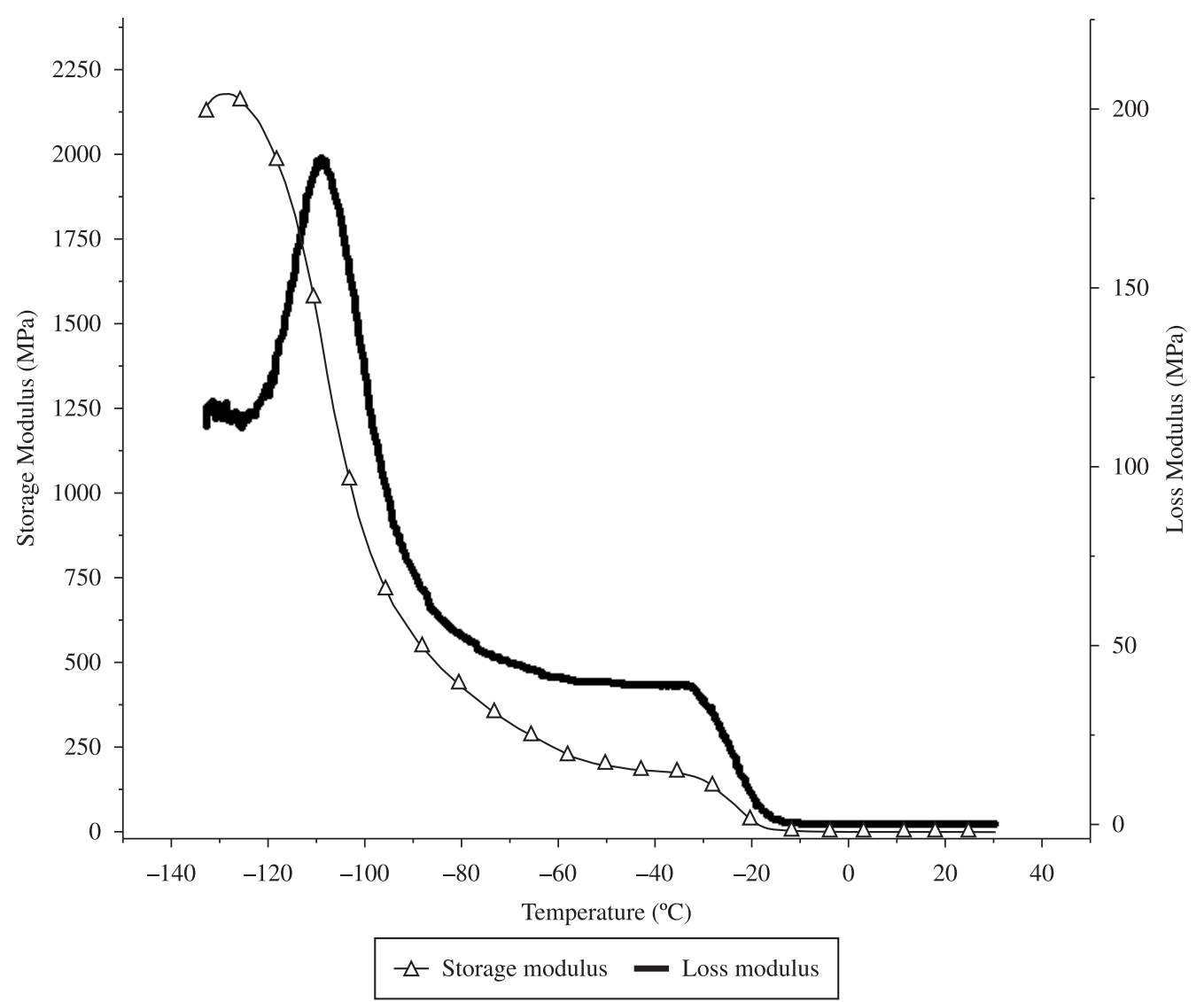

Figure 10. DMA of 12 and $24 \mathrm{kV}$ silicone surge arrester sample after aged salt spray. 


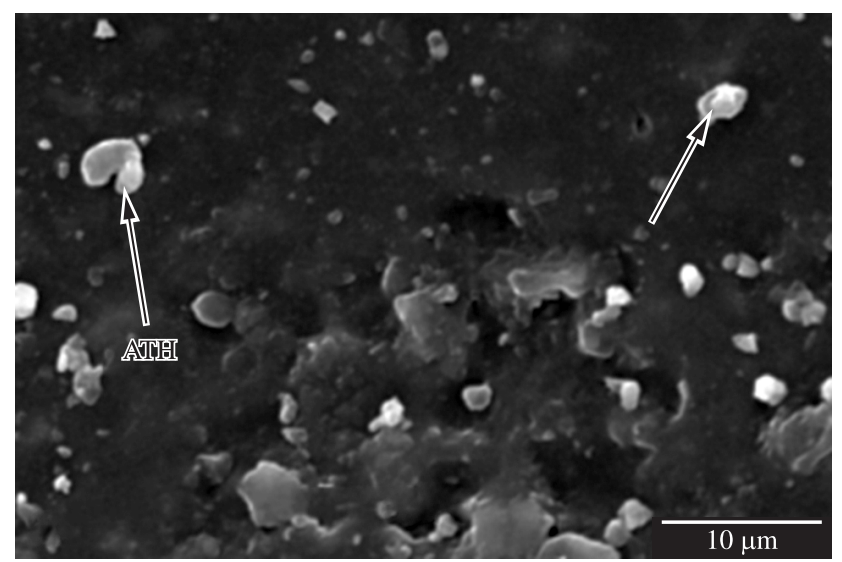

(a)

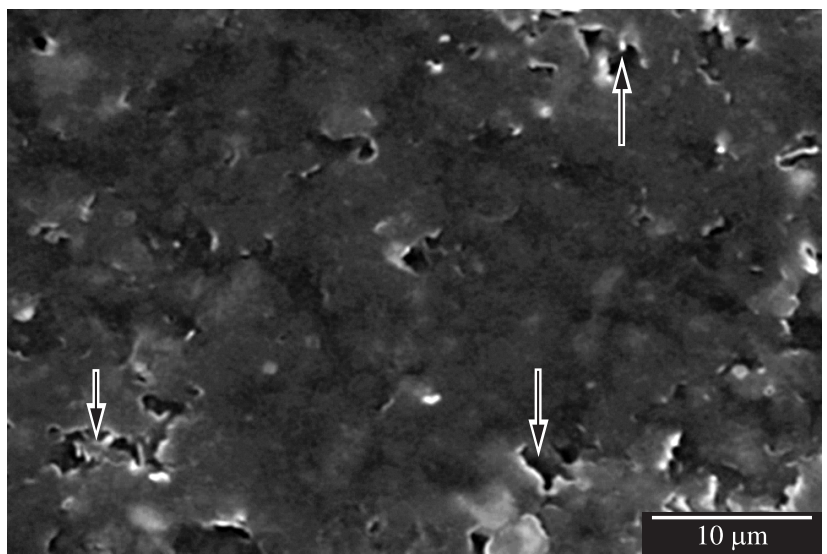

(b)

Figure 11. a) Surface of the new sample of silicone rubber, and b) the samples aged during 6 months in salt spray. a) Arrows indicate ATH particles; and b) holes after ATH particles removing.

hydrophobicity. The Figure 11b showed that ATH was absent from the SR surface, conducting to a decrease of the hydrophobicity and thus increased the possibility of leakage current.

Comparing the micrographs (Figure 11a,b) of silicone rubber, the filler (alumina trihydrate - ATH) has been removed during the aging experiment, causing degradation in the sample.

\section{Conclusions}

In this study the dynamical mechanical, thermal and electrical properties of polymeric insulators, surge arrester and the silicone rubber were investigated. It is expected that the polymer products will have longer durability in the field when adequate thermal and photo oxidation stabilizers are included by manufactures in its composition. The different silicone rubber submitted to aging by salt spray and cyclic heating have displayed only a remarkable surface degradation, the main modification been attributed to alumina trihydrate used as a filler in the composition of the polymer. ATH has been removed from the polymer as a consequence of the aging techniques adopted. The study developed in this work showed that there was no significant degradation of the main properties of the polymer, regarding sample that was taken from the field as well as the samples aged thermally.

\section{Acknowledgement}

Authors would like to thanks to ANEEL Agência Nacional de Energia Elétrica and Rio Grande Energia S.A. for the financial support for the development of this study.

\section{References}

1. Wallstro, S.; Dernfalk, A. D.; Bengtsson, M.; Kro, S.; Gubanski, S. M. \& Karlsson, S. - Polym. Degrad. Stabil., 88, p.400 (2005).

2. Kumagai, S. - IEEE Trans. Dielectr. Electr. Insul., 14, p.1201 (2007). http://dx.doi.org/10.1109/TDEI.2007.4339480

3. Kumagai, S. - IEEE Trans. Dielectr. Electr. Insul., 14, p.384 (2007). http://dx.doi.org/10.1109/TDEI.2007.344618

4. Haji, K.; Zhu, Y.; Otsubo, M. \& Sakoda, T. - Polym. Degrad. Stabil., 93, p.2214 (2008). http://dx.doi.org/10.1016/j. polymdegradstab.2008.05.025
5. Gubanski, S. M. - IEEE Trans. Electr. Insul., 27, p.374 (1992). http:// dx.doi.org/10.1109/14.135608

6. Kumagai, S. \& Yoshimura, N. - IEEE Trans. Dielectr. Electr. Insul., 8, p.673 (2001). http://dx.doi.org/10.1109/94.946722

7. Hillborgl, H. \& Gedde, U. W. - IEEE Trans. Dielectr. Electr. Insul., 6, p.703 (1999).

8. Ayman, H.; El-Hag, Jayaram, S. H. \& Cherney, E. A. - J. Electrost., 97, p.48 (2009).

9. Rowland, S. M.; Xiong, Y. \& Robertson, J. - IEEE Trans. Dielectr. Electr. Insul., 14, p.130 (2007). http://dx.doi.org/10.1109/TDEI.2007.302881

10. Meyer, L. H.; Cherney, E. A. \& Jayaram, E. A. - IEEE Elec. Insul. Mag., 20, p.13 (2004). http://dx.doi.org/10.1109/MEI.2004.1318835

11. American Society for Testing and Materials - ASTM. - "ASTM G26 - 96 - Standard Pratice for Operating Light Exposure apparatus (xenon-Arc Type) With and without water for exposure of Nonmetallic Materials", ASTM (1996).

12. American Society for Testing and Materials - ASTM. - "ASTM B 117 - 07a Standard Practice for Operating Salt Spray (Spray) Apparatus", $\operatorname{ASTM}(2007)$.

13. Ferreira, C. A.; Coser, E.; Angelini, J. M. G.; Rossi, J. A. D.; Arndt, O.; Martinez, M. L. B. \& Brito, F. - ISH, p.1 (2007).

14. Boonruang, M.; Hiroyuki, S. \& Ryosuke, M. - IEEE Trans. Dielectr. Electr. Insul., 13, p.129 (2006).

15. American Society for Testing and Materials - ASTM. - "ASTM D 1525 - 98 Standard Test Method for Vicat Softening Temperature of Plastics", ASTM (1998).

16. American Society for Testing and Materials - ASTM. - "ASTM E 1252 - 98 (Reapproved 2007) Standard Practice for General Techniques for Obtaining Infrared Spectra for Qualitative Analysis", ASTM (2007).

17. National Electrical Manufactures Association - NEMA107. - "Methods of Measurement of Radio Influence Voltage (RIV) of High Voltage Apparatus", NEMA.

18. Yoshimura, N. \& Kumagai, S. - IEEE Trans. Dielectr. Electr. Insul., 6, p.632 (1999). http://dx.doi.org/10.1109/94.798120

19. Sorqvist, T. \& Vlastos, A. E. - IEEE Trans. Power Deliv., 12, p.1657 (1997). http://dx.doi.org/10.1109/61.634187

Enviado: $14 / 12 / 10$

Reenviado: $27 / 03 / 11$

Aceito: $29 / 03 / 11$

DOI: 10.1590/S0104-14282011005000071 